\title{
SUS: Uma Análise Económico-Financeira
}

\author{
Yuri Gurgel Borba ${ }^{1}$ \\ Luis Carlos de Barros Loureiro ${ }^{1}$ \\ ${ }^{1}$ Universidade Federal Fluminense, Brasil; E-Mail: yuriborba@id.uff.br
}

\begin{abstract}
Resumo
Com a Constituição de 1988 a saúde no Brasil se tornou responsabilidade do Estado, promovendo aos cidadãos uma gama de direitos para garantir a sua qualidade de vida. Visando assegurar a execução dos deveres constitucionais foi criado o Sistema Único de Saúde (SUS). Com uma proposta de atendimento universal, integral e equânime além de contar com financiamento tripartite, onde Federação, Estado e Município se responsabilizam com os aportes necessários para o funcionamento, surge-se um oneroso e complexo sistema. Após cerca de trinta anos em funcionamento a sua efetividade é rotineiramente contestada, fazendo com que a presente monografia busque avaliar a viabilidade econômico-financeira do atual Sistema Único de Saúde. Para isto foi realizado uma pesquisa de revisão teórica nas bases legais e históricas do país além de uma análise financeira dos investimentos na saúde do município de Rio das Ostras - RJ. A partir da análise dos dados obtidos, foi constatado que o SUS é essencial em determinadas áreas e micro populações, entretanto, ainda carece de maiores investimentos em medidas prevencionistas além de uma administração técnico-cientifica com lisura e comprometimento.
\end{abstract}

Palavras-chave: análise econômico-financeira; saúde pública; sistemas de saúde; sistema único de saúde.

\begin{abstract}
With the constitution of 1998 the healthcare service in Brazil became a government responsibility, providing citizens a variety of rights to guarantee their quality of life. Looking to assure the constitutional rights it was created the Unified Health System (Sistema Único de Saúde - SUS). With a proposal of universal, integral, and equal healthcare, and the financial support provided by the federal, state, and local government to assure the required supplies for a proper operation, emerges a complex and onerous system. After about 30 years of operation the system efficiency is continually contested giving rise to the present study that aims to evaluate the economic-financial viability of the currently Unified Health System. It was done a literature review in the legal and historical basis of the country, and an analysis of the financial investments in the healthcare system of Rio das Ostras - RJ. From the analyses of the obtained data it was confirmed that the SUS is essential to certain areas and micro-populations, however, the system still demands more investments and preventive measures, as well as a technical and scientific administration with transparency and commitment.
\end{abstract}

Keywords: beconomic and financial analysis; health policy; public health; Unified Health System.

\section{Introdução}

A promoção da saúde no mundo durante séculos não era considerada responsabilidade do Estado, mas apenas incumbência individual (Paim, 2013). A partir da consolidação da Revolução Industrial e a modificação no modelo de produção surge-se uma nova percepção quanto o comprometimento da população ativa afetava as finanças do Estado, fazendo assim com que se começasse a desempenhar esforços relativos à manutenção da condição 
necessária da classe trabalhadora para a realização das atividades laborais. Com isso são estabelecidas medidas de recuperação da saúde buscando manter a disponibilidade da mão de obra e manutenção da produção (Funasa n.d.).

O Brasil com a chegada da década de oitenta, vivenciando um momento político histórico que clamava pela queda do regime militar e a realização de eleições, fruto do despertar de interesse das diversas camadas da sociedade, começa a desenvolver um senso de coletividade e responsabilidade estatal que até pouco tempo antes não era visto (Bertoncelo, 2009).

Com o transcorrer de diversas assembleias, fóruns e manifestações, é conquistada a promulgação da Constituição de 1988, em que no seu corpo textual são contemplados os deveres do Estado frente a diversas áreas como a saúde (Rocha, 1998).

Posteriormente, em 19 de setembro de 1990 surge a lei 8.080 que dispôs a cerca das condições para a promoção, proteção e recuperação da saúde, organização e o funcionamento dos serviços correspondentes. Regulando em todo o território nacional, as ações e serviços de saúde (Brasil, 1990).

Compreendendo que a constituição define como dever do Estado a saúde, faz-se necessário entender o seu conceito. A definição mais atual e aceita mundialmente é fruto da conferência internacional de saúde celebrada em Nova York no ano de 1946 (Sinus, 2014). Segundo a Organização Mundial de Saúde (1946) "a saúde é um estado completo de bem-estar físico, mental e social e não apenas a ausência de doença ou enfermidade".

Reconhecendo a complexidade da caracterização do termo saúde, com a incumbência do estado estabelecida na constituição de 1988 de dever garantir acesso à saúde a todos sem distinção, através da criação de um sistema público universal e gratuito (o SUS), alinhado ao crescimento exponencial da população brasileira e as eventuais crises nas esferas municipais, estaduais e federal surgem contestações quanto à viabilidade de proporcionar a todos os indivíduos a promoção integral da sua saúde.

\section{Objetivos}

\subsection{Objetivo Geral}

Analisar o SUS brasileiro focando na sua gestão econômico-financeira e o seu gerenciamento, a fim de entender a sua atual situação funcional.

\subsection{Objetivos Específicos}

Avaliar as políticas econômicas que estão ligadas ao financiamento do SUS. Demonstrar a relação dos aportes no sistema e a qualidade de vida através da análise de correlação do índice de desenvolvimento humano (IDH) com os investimentos em saúde.

\subsection{Aspectos Metodológicos Envolvidos}

Trata-se de uma pesquisa de revisão teórica nas bases legais e históricas da saúde brasileira focando na responsabilidade estatal adquirida e uma análise quantitativa dos investimentos realizados em saúde. A análise quantitativa primeiramente estabeleceu um paralelo entre os investimentos realizados em saúde no Brasil, por meio de uma comparação entre as receitas totais no exercício atual e o valor empregado na área. Posteriormente, uma avaliação das despesas estabelecidas na Lei orçamentária anual exercício 2017 do município de Rio das Ostras - RJ.

Por fim, com o levantamento dos dados houve a realização de uma análise estatística através do coeficiente de correlação de Pearson para descobrir se existe relação entre a variável investimento em saúde e IDH.

\section{Modelo Político Financeiro Atual do SUS}

\subsection{Constituição de 1988}

A vigente Carta Magna do país é a sétima já promulgada e veio para consolidaro regime democrático estabelecido em 1985. Elaborada por um Congresso constituinte composto por 559 parlamentares eleitos democraticamente, teve como marco histórico a participação popular na sua formulação. Com o decorrer dos anos passou a ser 
conhecida com a alcunha de "constituição cidadã", por ter em seu corpo textual diversas questões tachadas de progressistas contempladas, garantindo assim inúmeros direitos individuais (Brasil, 2015).

Nessa construção a saúde tem seu papel de destaque, onde segundo Brasil (2016):

Art. 196. A saúde é direito de todos e dever do Estado, garantido mediante políticas sociais e econômicas que visem à redução do risco de doença e de outros agravos e ao acesso universal e igualitário às ações e serviços para sua promoção, proteção e recuperação. Art. 197. São de relevância pública as ações e serviços de saúde, cabendo ao Poder Público dispor, nos termos da lei, sobre sua regulamentação, fiscalização e controle, devendo sua execução ser feita diretamente ou através de terceiros e, também, por pessoa física ou jurídica de direito privado. Art. 198. As ações e serviços públicos de saúde integram uma rede regionalizada e hierarquizada e constituem um sistema único, organizado de acordo com as seguintes diretrizes: I - descentralização, com direção única em cada esfera de governo; II - atendimento integral, com prioridade para as atividades preventivas, sem prejuízo dos serviços assistenciais; III participação da comunidade.

Surgindo assim o SUS, um sistema descentralizado, integral e que conta com a participação da comunidade em sua construção (Brasil, 1988).

O seu financiamento é realizado de forma tripartite, ou seja, sua responsabilidade se dá através de recursos da seguridade social, da União, dos Estados, do Distrito Federal e dos Municípios (Brasil, 1988).

Por fim, essa mesma constituição permite a instituições de iniciativa privada complementar o SUS em sua assistência em saúde, desde que siga suas diretrizes (Brasil, 1988).

\subsection{Financiamento do Sistema Único de Saúde (SUS)}

Aprofundando no financiamento tripartite do SUS, onde a responsabilidade de custear as despesas referentes aos serviços públicos de saúde encontra-se escorada nas esferas federal, estadual e municipal, observa-se uma questão complexa de receitas para a tentativa de suprir as necessidades financeiras (FIOCRUZ n.d.).

O artigo 198 da constituição federal detalha que:

$\S 1$ 1․ O Sistema Único De Saúde será financiado, nos termos do art. 195, com recursos do orçamento da seguridade social, da União, dos Estados, do Distrito Federal e dos Municípios, além de outras fontes. (Parágrafo único renumerado para § 10 pela Emenda Constitucional № 29, de2000).

§ 2o A União, os Estados, o Distrito Federal e os Municípios aplicarão, anualmente, em ações e serviços públicos de saúde recursos mínimos derivados da aplicação de percentuais calculados sobre: (Incluído pela Emenda Constitucional no 29, de 2000)"

I - no caso da União, a receita corrente líquida do respectivo exercício financeiro, não podendo ser inferior a 15\% (quinze por cento); (Redação dada pela Emenda Constitucional no 86, de 2015)(g.n.)

II - no caso dos Estados e do Distrito Federal, o produto da arrecadação dos impostos a que se refereo art. 155 e dos recursos de que tratam os arts. 157 e 159, inciso I, alínea a, e inciso II, deduzidas as parcelas que forem transferidas aos respectivos Municípios; (Incluído pela Emenda Constitucional no 29, de 2000)

III - no caso dos Municípios e do Distrito Federal, o produto da arrecadação dos impostos a que se refere o art. 156 e dos recursos de que tratam os arts. 158 e 159, inciso I, alínea b e § 3‥(Incluído pela Emenda Constitucional № 29, de 2000)

Em 13 de janeiro de 2012 é promulgada a lei complementar no 141 que regulamenta o artigo 198 da Constituição Federal e que estabelece aplicações mínimas em ações e serviços públicos em saúde para os Estados, Distrito Federal e Municípios (Brasil, 2016).

A lei complementar 141 determina em seus artigos 6ㅇ e 7우 que:

Art. 6o Os Estados e o Distrito Federal aplicarão, anualmente, em ações e serviços públicos de saúde, no mínimo, 12\% (doze por cento) da arrecadação dos impostos a que se refere o art. 155 e dos recursos de 
que tratam o art. 157, a alínea "a" do inciso I e o inciso II do caput do art. 159, todos da Constituição Federal, deduzidas as parcelas que forem transferidas aos respectivos Municípios. Art. 7o Os Municípios e o Distrito Federal aplicarão anualmente em ações e serviços públicos de saúde, no mínimo, 15\% (quinze por cento) da arrecadação dos impostos a que se refere o art. 156 e dos recursos de que tratam o art. 158 e a alínea "b" do inciso I do caput e o § 3 do art. 159, todos da Constituição Federal.

Quanto à aplicação mínima da União, é definida a partir da Emenda Constitucional n 86 de 17 de março de 2015, artigo 2o que:

Art. 2ㅇ O disposto no inciso I do § 2ㅇ do art. 198 da Constituição Federal será cumprido progressivamente, garantidos, no mínimo:

I - 13,2\% (treze inteiros e dois décimos por cento) da receita corrente líquida no primeiro exercício financeiro subsequente ao da promulgação desta Emenda Constitucional; II - 13,7\% (treze inteiros e sete décimos por cento) da receita corrente líquida no segundo exercício financeiro subsequente ao da promulgação desta Emenda Constitucional; III - 14,1\% (quatorze inteiros e um décimo por cento) da receita corrente líquida no terceiro exercício financeiro subsequente ao da promulgação desta Emenda Constitucional; IV - 14,5\% (quatorze inteiros e cinco décimos por cento) da receita corrente líquida no quarto exercício financeiro subsequente ao da promulgação desta Emenda Constitucional; V - 15\% (quinze por cento) da receita corrente líquida no quinto exercício financeiro subsequente ao da promulgação desta Emenda Constitucional.

\subsection{Lei 8080 de 19 de Setembro de 1990}

Posteriormente a constituição surge à lei 8.080 que dispõe a cerca das condições para a promoção, proteção e recuperação da saúde, organização e o funcionamento dos serviços correspondentes. Regulando em todo o território nacional, as ações e serviços de saúde (Brasil, 1990)

Segundo Brasil (1990):

Art. 2 A saúde é um direito fundamental do ser humano, devendo o Estado prover as condições indispensáveis ao seu pleno exercício.

$\S 1$ ㅇ O dever do Estado de garantir a saúde consiste na formulação e execução de políticas econômicas e sociais que visem à redução de riscos de doenças e de outros agravos e no estabelecimento de condições que assegurem acesso universal e igualitário às ações e aos serviços para a sua promoção, proteção e recuperação.

$\S 2$ 2 0 dever do Estado não exclui o das pessoas, da família, das empresas e da sociedade. Art. 3o Os níveis de saúde expressam a organização social e econômica do País, tendo a saúde como determinantes e condicionantes, entre outros, a alimentação, a moradia, o saneamento básico, o meio ambiente, o trabalho, a renda, a educação, a atividade física, o transporte, o lazer e o acesso aos bens e serviços essenciais.

Corroborando com a Constituição, a lei vem reiterando a responsabilidade do Estado, reconhecendo a complexidade envolvida frente à promoção de saúde e não apenas a resolução de agravos iminentes.

Quanto ao financiamento, Brasil (1990) traz que "o orçamento da seguridade social destinará ao SUS de acordo com a receita estimada, os recursos necessários à realização de suas finalidades".

\subsection{Projeto de Emenda Constitucional (PEC) 241}

Com a crise que assola a economia do país e um novo governo pós-impeachment que conta com uma grande base política, o governo federal buscando limitar seus gastos para as próximas duas décadas faz a proposição da PEC 241.

Conhecida como PEC do teto de gastos, a medida que no final de outubro de 2016 prossegue para aprovação no senado visando a longo prazo equilibrar as contas públicas e amenizar o atual desequilíbrio fiscal existente. 
De acordo com o Projeto de Lei 241 (2016)

Art. 102. Será fixado, para cada exercício, limite individualizado para a despesa primária total do Poder Executivo, do Poder Judiciário, do Poder Legislativo, inclusive o Tribunal de Contas da União, do Ministério Público da União e da Defensoria Pública da União. § 1ㅇ№s Poderes e órgãos referidos no caput, estão compreendidos os órgãos e as entidades da administração pública federal direta e indireta, os fundos e as fundações instituídos e mantidos pelo Poder Público e as empresas estatais dependentes.

Com os limites estabelecidos e possíveis punições definidas, a PEC vem sofrendo inúmeras críticas de diversos setores da sociedade civil, sendo estes responsáveis por diversas manifestações e ocupações em todo o país. A principal motivação são as possíveis perdas consideráveis de recursos financeiros durante as próximas duas décadas em setores que desempenham papel de relevância e necessidade para a consolidação de uma sociedade com qualidade de vida. Destaca-se entre os setores que vem demandando maior preocupação a saúde e educação.

No âmbito da saúde, com a consolidação da PEC 241 os recursos ficarão limitados carecendo ainda mais de uma gestão profissional que mantenha um bom gerenciamento e administração das verbas para o funcionamento adequado dos programas do Ministério da Saúde.

Segundo Conasems (2016) estima-se que nos próximos vinte anos a retração de recursos financeiros cheguem a um montante superior aos 600 bilhões, comprometendo ainda mais a situação funcional do SUS, haja vista que com o desinvestimento em todas as áreas pela PEC espera-se que mais cidadãos procurem a saúde publica.

Tabela 1. Previsão de Impacto da PEC 241

\begin{tabular}{|c|c|c|c|}
\hline & Estado & Municipios & Estados e Municipios \\
\hline ACRE & $-1.467 .577 .222,94$ & $-790.173 .860,93$ & $-2.257 .751 .083,87$ \\
\hline ALAGOAS & $-1.551 .212 .972,26$ & $-6.519 .021 .034,20$ & $-8.070 .234 .006,46$ \\
\hline AMAZONAS & $-3.668 .751 .149,07$ & $-2.983 .271 .934,90$ & $-6.652 .023 .083,97$ \\
\hline AMAPA & $-644.100 .119,27$ & $-993.139 .764,29$ & $-1.637 .239 .883,56$ \\
\hline ВАНIA & $-9.314 .897 .057,04$ & $-21.232 .332 .493,52$ & $-30.547 .229 .550,57$ \\
\hline CEARA & $-2.514 .030 .281,07$ & $-17.127 .292 .668,94$ & $-19.641 .322 .950,01$ \\
\hline DISTRITO FEDERAL & $-4.486 .542 .306,50$ & 0,00 & $-4.486 .542 .306,50$ \\
\hline ESPIRTOO SANTO & $-3.735 .130 .140,99$ & $-3.648 .437 .363,58$ & $-7.383 .567 .504,58$ \\
\hline GOIAS & $-627.853 .268,32$ & $-12.708 .438 .982,81$ & $-13.336 .292 .251,13$ \\
\hline MARANHAO & $-2.273 .737 .034,74$ & $-10.666 .618 .395,69$ & $-12.940 .355 .430,43$ \\
\hline MINAS GERAIS & $-8.054 .149 .161,84$ & $-37.778 .206 .090,25$ & $-45.832 .355 .252,09$ \\
\hline MATO GROSSO DO SUL & $-916.791 .720,32$ & $-5.508 .079 .437,15$ & $-6.424 .871 .157,47$ \\
\hline MATO GROSSO & $-1.637 .737 .823,22$ & $-5.272 .947 .771,38$ & $-6.910 .685 .594,59$ \\
\hline PARA & $-1.450 .413 .905,65$ & $-12.062 .280 .142,22$ & $-13.512 .694 .047,87$ \\
\hline PARAIBA & $-863.285 .589,36$ & $-8.369 .578 .614,84$ & $-9.232 .864 .204,21$ \\
\hline PERNAMBUCO & $-7.233 .134 .363,61$ & $-15.266 .634 .944,34$ & $-22.499 .769 .307,95$ \\
\hline PIAUI & $-1.239 .678 .818,54$ & $-7.172 .031 .109,14$ & $-8.411 .709 .927,68$ \\
\hline PARANA & $-7.826 .107 .732,41$ & $-17.043 .877 .542,33$ & $-24.869 .985 .274,73$ \\
\hline RO DE LANBRO & $-4.179 .810 .330,06$ & $-28.037 .070 .078,31$ & $-32.216 .880 .408,37$ \\
\hline RO GRANDE DO NORTE & $-1.538 .850 .948,79$ & $-6.172 .773 .163,28$ & $-7.711 .624 .112,07$ \\
\hline RONDONIA & $-1.370 .557 .541,44$ & $-2.273 .518 .963,33$ & $-3.644 .076 .504,77$ \\
\hline RORAIMA & $-676.758 .623,56$ & $-636.416 .552,33$ & $-1.313 .175 .175,89$ \\
\hline RO GRANDE DO SUL & $-6.261 .494 .022,25$ & $-16.612 .815 .077,80$ & $-22.874 .309 .100,05$ \\
\hline SANTA CATARNA & $-3.728 .341 .346,45$ & $-11.417 .954 .949,46$ & $-15.146 .296 .295,91$ \\
\hline SERGIPE & $-1.052 .934 .928,01$ & $-4.155 .268 .565,75$ & $-5.208 .203 .493,76$ \\
\hline SAO PAULO & $-31.876 .550 .953,91$ & $-52.155 .820 .321,93$ & $-84.032 .371 .275,84$ \\
\hline TOCANTINS & $-1.803 .184 .436,58$ & $-2.266 .253 .301,13$ & $-4.069,437.737,71$ \\
\hline TOTAL & $-111.993 .613 .798,18$ & $-308.870 .253 .123,81$ & $-420.863 .866 .921,99$ \\
\hline
\end{tabular}

Fonte: Conasems, 2016 


\subsection{Agência Nacional de Saúde Suplementar (ANS)}

A ANS surge posteriormente à consolidação do SUS na constituição de 1988 através da lei 9961 de 28 de janeiro de 2000. Vinculada ao Ministério da Saúde a agência tem por finalidade defender o interesse público na assistência suplementar em saúde, regulando por meio de um conjunto de medidas e ações os mercados explorados pelas empresas (ANS, 2016).

Dentre as inúmeras funções estabelecidas para a ANS, destaca-se para a continuidade deste trabalho e o seu sentido o exposto no art.32 da lei 9.656 de 3 de junho de 1998:

Art. 32. Serão ressarcidos pelas operadoras dos produtos de que tratam o inciso I e o § 10 do art. 1 o desta Lei, de acordo com normas a serem definidas pela ANS, os serviços de atendimento à saúde previstos nos respectivos contratos, prestados a seus consumidores e respectivos dependentes, em instituições públicas ou privadas, conveniadas ou contratadas, integrantes do Sistema Único de Saúde - SUS § 100 ressarcimento será efetuado pelas operadoras ao SUS com base em regra de valoração aprovada e divulgada pela ANS, mediante crédito ao Fundo Nacional de Saúde - FNS § 2o Para a efetivação do ressarcimento, a ANS disponibilizará às operadoras a discriminação dos procedimentos realizados para cada consumidor.

Torna-se assim o ressarcimento ao SUS uma obrigação aos planos de saúde quando um de seus beneficiários usufruírem do sistema. Os valores ressarcidos retomam como investimento na saúde publica, contribuindo parcialmente com o alívio do financiamento.

\section{Análise Econômico-Financeira do SUS}

\subsection{Análise Financeira do SUS no Brasil}

O financiamento tripartite do SUS como já mencionando conta com uma parcela federal na composição de suas receitas, onde esta esfera é responsável pela movimentação das maiores cifras.

Através da Lei 13.255 de 2016 foram previstos gastos na casa dos 118 bilhões de reais para a pasta da saúde no exercício anual, onde pela primeira vez nos últimos 5 anos houve uma redução na verba prevista quando se comparado ao ano anterior.

Segundo as Leis Orçamentarias anuais foram previstos os seguintes investimentos:

Tabela 2. Orçamento Previsto para o Ministério da Saúde (R\$) x Receita Total (R\$)

\begin{tabular}{|c|c|c|c|}
\hline Ano & Ministério da Saúde (R\$) & Receita Total (R\$) & $\%$ \\
\hline 2016 & $118.472 .839 .832^{*}$ & 2.953 .546 .387 .308 & $4,01^{*}$ \\
\hline 2015 & 121.011 .373 .943 & 2.876 .676 .947 .442 & 4,20 \\
\hline 2014 & 106.019 .264 .465 & 2.383 .177 .997 .310 & 4,44 \\
\hline 2013 & 99.272 .350 .163 & 2.165 .910 .805 .669 & 4,58 \\
\hline 2012 & 91.754 .806 .614 & 2.150 .458 .867 .507 & 4,26 \\
\hline
\end{tabular}

* As verbas previstas foram reduzidas através de medidas assinadas pelo presidente interino Fonte: Elaborado pelo autor embasado nas LOA

Como se pode observar no Gráfico I, o Brasil nos últimos cinco anos comprometeu cerca de $4 \%$ da sua receita total com Saúde, gastando cerca de R\$ 294 milhões diariamente para o funcionamento da pasta. 
Gráfico 1. Orçamento Previsto para o Ministério da Saúde (\%) x Receita Total (\%)

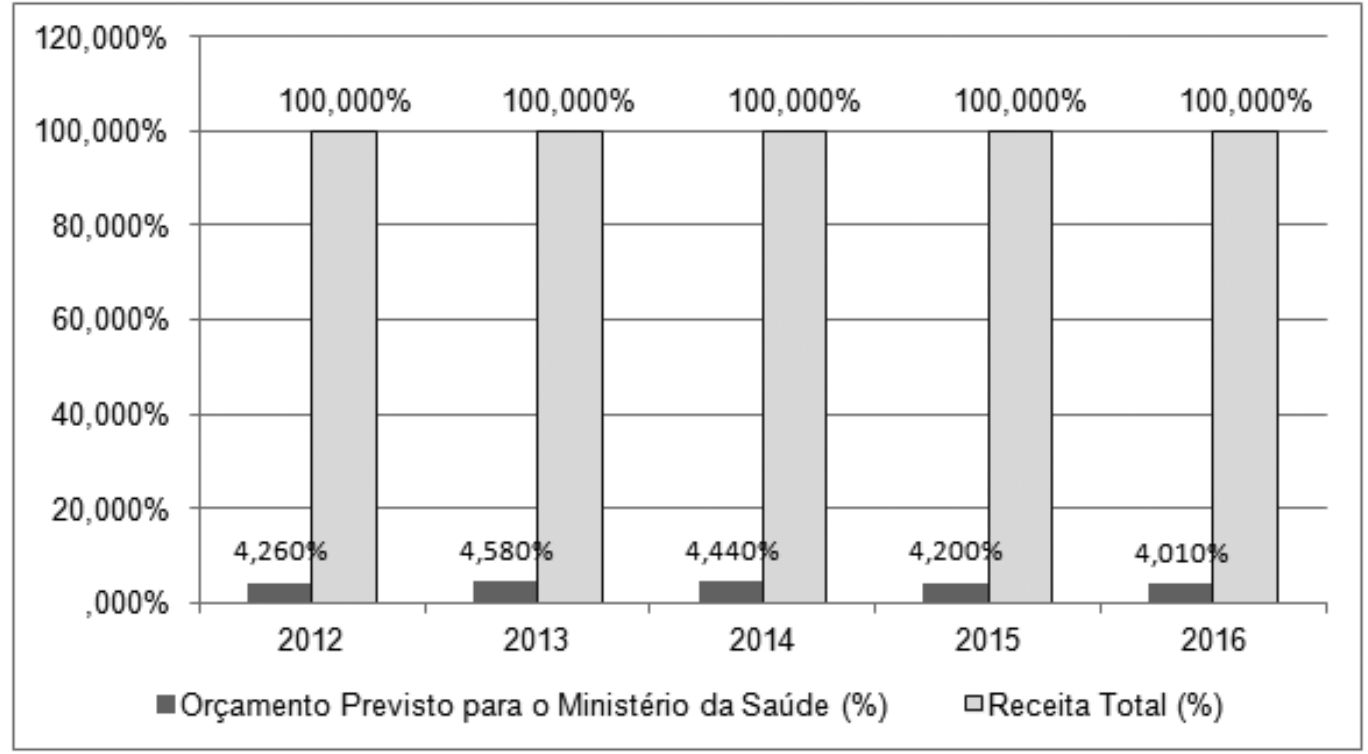

Fonte: Elaborado pelo autor embasado nas LOA

\subsection{Os Investimentos em Saúde no Mundo e a Qualidade de Vida}

Ao observar a tabela III percebe-se que os investimentos em saúde retornam em qualidade de vida para o cidadão. Países considerados como de primeiro mundo anualmente investem parcela significativa de suas receitas neste propósito resultando em discrepantes realidades quando se comparado com os indicadores de vida de países que não contam com uma disponibilização alta de recursos.

Para estabelecer uma comparação entre os países, utiliza-se IDH elaborado pelo Programa das Nações Unidas para o Desenvolvimento (PNUD) que tem como um de seus objetivos justamente medir a qualidade de vida oferecida a população.

Conforme a tabela III mostra, nota-se que quanto menos é investido em Saúde menor o IDH no país, resultando também em uma menor expectativa de vida para seus cidadãos.

Tabela 3. Gastos em Saúde em dólar americano (US\$) e resultados de qualidade de vida

\begin{tabular}{|c|c|c|c|c|}
\hline País & $\begin{array}{c}\text { Gasto em Saúde em } \\
\text { US\$ }\end{array}$ & Expectativa de vida & \% do PIB em Saúde & IDH \\
\hline Afeganistão & 167 & 60,5 & 8,2 & 0,465 \\
\hline Alemanha & 5182 & 81 & 11,3 & 0,916 \\
\hline Angola & 239 & 52,5 & 3,3 & 0,532 \\
\hline Argentina & 1137 & 76,5 & 4,8 & 0,836 \\
\hline Brasil & 1318 & 75 & 8,3 & 0,755 \\
\hline Camarões & 122 & 57,5 & 4,1 & 0,512 \\
\hline Cuba & 2475 & 79 & 11,1 & 0,769 \\
\hline Dinamarca & 4,782 & 80,5 & 5,6 & 0,69 \\
\hline Egito & 594 & 71 & 4,9 & 0,442 \\
\hline Etiopia & 73 & 65 & 17,1 & 0,915 \\
\hline EUA & 9403 & 79,5 & 3,6 & 0,579 \\
\hline Gana & 145 & 62,6 & 5,6 & 0,411 \\
\hline Guiné & 68 & 59 & 7,6 & 0,483 \\
\hline Haiti & 131 & 64 & & \\
\hline
\end{tabular}




\begin{tabular}{|c|c|c|c|c|}
\hline Italia & 3239 & 82,5 & 9,2 & 0,873 \\
\hline Luxemburgo & 6812 & 82 & 6,9 & 0,892 \\
\hline Noruega & 6347 & 82 & 9,7 & 0,944 \\
\hline Suécia & 5219 & 82,5 & 11,9 & 0,907 \\
\hline Suíça & 6468 & 83 & 11,7 & 0,93 \\
\hline
\end{tabular}

Fonte: Elaborado pelo autor embasado na OMS (2014) e PNUD (2015).

Ao se verificar a existência de relação entre as variáveis "gastos em saúde" e IDH através de um instrumento estatístico conhecido como coeficiente de correlação de Pearson obtém-se $R=0,75$. $O$ resultado indica uma forte correlação entre as variáveis, ou seja, quanto maior o investimento em saúde maior probabilidade de ter um IDH mais elevado no país e consequentemente melhores condições de se viver.

\subsection{Análise Financeira do SUS no Município de Rio das Ostras}

De acordo com o IBGE (2010) o município de Rio das ostras - RJ foi uma das cidades que mais cresceram em população no Brasil. Com crescimento em cerca de 11,4\% ao ano, sua população triplicou na última década, fruto da forte alta na indústria petrolífera instalada na cidade vizinha, Macaé.

Entretanto, mesmo com as dificuldades encontradas com o aumento repentino de usuários do SUS é observado através de indicadores de Saúde do Estado que em determinadas áreas os esforços do sistema vem rendendo bons resultados.

A queda na mortalidade infantil é um dos grandes feitos que se possa comemorar no país (IBGE, 2013). Sendo uma das metas pactuadas através do encontro entre lideres de 189 países em 2002, durante a confecção das metas do milênio que buscava promover a melhoria de padrão de vida da população mundial teve atenção redobrada no Brasil, resultando em números satisfatórios no decorrer dos anos. Como se pode observar na Tabela IV, Rio das Ostras trilhou esse mesmo caminho:

Tabela 4. Taxa de Mortalidade Infantil ao ano em Rio das Ostras

\begin{tabular}{cc}
\hline Ano & Taxa \\
\hline 2001 & 11,31 \\
\hline 2002 & 13,85 \\
\hline 2003 & 16,71 \\
\hline 2004 & 10,82 \\
\hline 2005 & 9,61 \\
\hline 2006 & 11,28 \\
\hline 2007 & 12,15 \\
\hline 2008 & 11,16 \\
\hline 2009 & 15,81 \\
\hline 2010 & 6,81 \\
\hline 2011 & 7,87
\end{tabular}

Fonte: Secretaria de Estado de Saúde do Rio de Janeiro

Nota: Os dados de 2011 são preliminares, com situação em 14/02/13, sujeitos a retificação e recebimento de informações de óbitos de residentes no RJ ocorridos em outros estados e de nascimentos ocorridos em outros estados, de mães residentes no RJ

Muito desse sucesso se deve ao Programa Nacional de Imunização que consolidou medidas prevencionistas aos indivíduos de todas as idades. O atendimento universal visto no corpo textual da constituição é visualizado diariamente, onde todos os cidadãos brasileiros sejam eles portadores de planos de saúde ou não, usufruem do programa de vacinação. 
Entretanto, os resultados positivos não acompanham todas as áreas do Município, programas como o de Estratégia e Saúde da Família (ESF) que oferecem o atendimento primário ao usuário tem cobertura mínima, não diferenciando tanto do programa de Saúde Bucal como se pode notar na tabela V:

Tabela 5. Cobertura de Serviços de Saúde em Rio das Ostras

\begin{tabular}{cc}
\hline Serviço & Cobertura (\%) \\
\hline Atenção Básica (ESF) & 16,22 \\
\hline Saúde Bucal & 18,22 \\
\hline V. Tríplice Viral & 79,89 \\
\hline V. Tetravalente & 87,86 \\
\hline V. Influenza & 87,86
\end{tabular}

Fonte: Secretaria de Estado de Saúde do Rio de Janeiro

Nota: $\mathrm{V}=$ vacinação

Atualmente, não contando com suas antigas principais fontes de receita, estas derivadas de royalties, que se encontra em baixa e tendo que lidar com os inúmeros serviços a serem prestados a população, a cidade vem encontrando dificuldades para o planejamento do próximo ano, tendo como o principal problema o futuro da Saúde Municipal. Segundo o Projeto de Lei orçamentaria anual exercício 2017 estima-se receita no montante de meio bilhão de reais.

Tabela 6. Orçamento para a Saúde (R\$) x Receita Total (R\$)

\begin{tabular}{cccc}
\hline Natureza da despesa & Valor Total Previsto (R\$) & Receita Total (RS) & $\%$ \\
\hline Saúde & 112.457 .090 & 562.108 .900 & 20,00 \\
\hline
\end{tabular}

Fonte: Elaborado pelo autor embasado no projeto de lei orçamentaria anual 2017

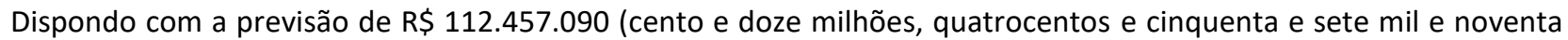
reais) o Município empregará cerca de $20 \%$ de sua receita total exclusivamente para a pasta da saúde, buscando garantir aos cidadãos os direitos conquistados na Constituição Federal e cumprir o seu dever.

Ao avaliar esse orçamento observa-se no Gráfico II que cerca de $14 \%$ dos gastos, que equivalem a $\mathrm{R} \$ 15.8826 .330$ (quinze milhões, oitocentos e vinte e seis mil e trezentos e trinta reais) são oriundos do repasse de verbas Estadual e Federal.

Tabela 7. Resumo das Receitas por Fonte

\begin{tabular}{cc}
\hline Origem & Valor (R\$) \\
\hline Ordinário & 74.940 \\
\hline Royalties - Lei 7990/89 & 35.000 \\
\hline Royalties - Lei 9478/97 & 265.300 \\
\hline SUS/Estado & 595.660 \\
\hline SUS/Invest & 1.719 .200 \\
\hline SUS/MAC (Média e alta complexidade) & 3.821350 \\
\hline SUS/VGS (Vigilância em Saúde) & 7.563 .610 \\
\hline SUS/AFB (Atenção Farmacêutica básica) & 1.112 .710 \\
\hline SUS/GS (Gestão do SUS) & 616.060 \\
\hline Total Por fontes de Recursos & 22.500 \\
\hline
\end{tabular}

Fonte: Elaborado pelo autor embasado no projeto de lei orçamentaria anual 2017

Continuando a análise, ao retirar as receitas das outras esferas, nota-se que o município através das suas fontes próprias se responsabiliza em arcar com $\mathrm{R} \$ 96.630 .760$ (noventa e seis milhões, seiscentos e trinta mil e setecentos e sessenta reais) contribuindo assim com cerca de $84 \%$ da verba prevista para a pasta. 


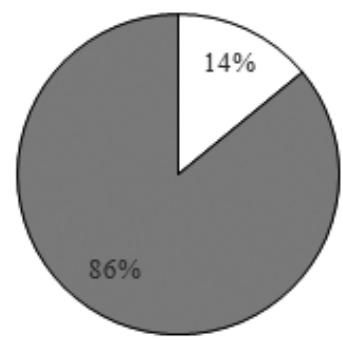

\section{$\square$ Receitas Repassadas pelo Estado e Federação $\quad \square$ Receitas Próprias}

Figura 3. Origem das Receitas de Financiamento

Fonte: Elaborado pelo autor embasado no projeto de lei orçamentaria anual 2017

Observando através de uma perspectiva mais individual é como se fossem investidos para manter diariamente a saúde de cada um dos 136.626 hipotéticos cidadãos riostrenses cerca de $\mathrm{R} \$ 2,29$, o que corresponderia mensalmente a $\mathrm{R} \$ 68,59$, valor este ínfimo quando comparado ao que seria pago para ter em um plano de saúde privado que ofereça toda a gama de serviços que o SUS oferece.

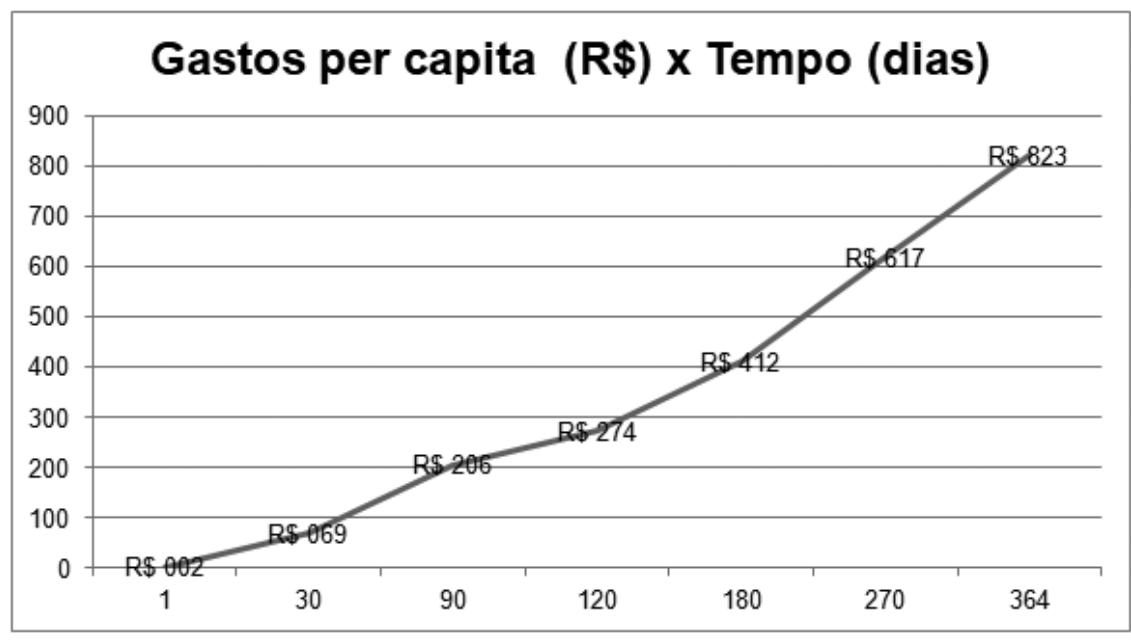

Figura 4. Gastos per capita

Fonte: Elaborado pelo autor embasado no projeto de lei orçamentaria anual 2017

\section{Considerações finais}

O SUS em sua construção teórica é um sistema referência em nível mundial. A promessa de um serviço universal, integral, equânime e que conta com a participação popular para adequações que possibilite um melhor atendimento é sensacional, infelizmente ainda carece de muitas mudanças para funcionar com excelência no dia-a-dia.

O primeiro problema observado é fruto da dimensão continental do Brasil e sua grande população, que em sua composição contempla uma miscigenação étnica com demandas características e que necessitam constantemente de políticas específicas.

O problema seguinte e provavelmente um dos maiores, ou talvez o maior que se observa, é a complexidade no seu financiamento e a onerosidade que o sistema envolve. Toma-se, por exemplo, o município de Rio das ostras que mesmo contando com cerca de $\mathrm{R} \$ \mathbf{3 0 0 . 0 0 0 , 0 0}$ (trezentos mil reais) para cada dia de 2016 passou por constantes dificuldades sendo elas materiais, estrutura, pessoal e de equipamento, comprometendo assim o resultado final da prestação de assistência.

Outro ponto destacável é fruto de um problema reconhecidamente nacional, por muitos considerado cultural, que é a falta de transparência no gerenciamento dos recursos. 
Por fim, observa-se que o SUS é essencial em determinadas áreas e micro populações além de fornecer certa segurança a toda população, entretanto, para a sua consolidação e reconhecimento como sistema de ponta ainda carece de maiores investimentos, com ênfase em medidas prevencionistas além de necessitar de uma administração técnico-cientifica com lisura e comprometimento.

\section{Referências}

Bertoncelo, E. E. (2009). Eu quero votar para presidente: uma análise sobre a Campanha das Diretas. Lua Nova (76): 169-196. Acedido a 24 de julho de 2017. Retrieved from http:// dx.doi.org/10.1590/S0102-64452009000100006.

Brasil. 1988. Constituição da República Federativa do Brasil. Atlas. Brasília: Senado.

Brasil. (2016). Agência Nacional de Saúde Suplementar. Acedido a 18 de outubro de 2016. Retrieved from. http://www.ans.gov.br/aans.

Brasil. (1990). Lei 8080/90: Brasília. Acedido a 21 de setembro de 2016. Retrieved from https://www.planalto. gov.br/ccivil_03/LEIS/L8080.html

Brasil. (1990). Lei n.o 8142: Dispõe sobre a participação da comunidade na gestão do Sistema Único de Saúde - SUS e sobre as transferências intergovernamentais de recursos financeiros na área da saúde e dá outras providências. Diário Oficial da União, Brasília.

Brasil. (2012). Lei n.o 12.595: Estima a receita e fixa a despesa da União para o exercício financeiro de 2012 . Diário Oficial da União, Brasília.

Brasil. (2013). Lei n.o 12.798: Estima a receita e fixa a despesa da União para o exercício financeiro de 2013 . Diário Oficial da União, Brasília.

Brasil. (2014). Lei n.o 12.952: Estima a receita e fixa a despesa da União para o exercício financeiro de 2014 . Diário Oficial da União, Brasília.

Brasil. (2015). Lei n.o 13.115: Estima a receita e fixa a despesa da União para o exercício financeiro de 2015. Diário Oficial da União, Brasília.

Brasil. (2016). Lei n.o 13.255: Estima a receita e fixa a despesa da União para o exercício financeiro de 2016 . Diário Oficial da União, Brasília.

CONASEMS (Conselho Nacional de Secretários Municipais de Saúde.) (2016). Nota sobre a proposta de emenda constitucional 241/2016. Acedido a 21 de setembro de 2016 . Retrieved from. http://www.conasems.org.br/images/NOTA_SOBRE_PEC_241_08ago16.pdf

EPM (Escola Paulista de Magistratura). (2016). O sistema único de saúde. Acedido a 18 de outubro de 2016. Retrieved from. http://www.epm.tjsp.jus.br/Sociedade/Saude.aspx

FUNASA (Fundação Nacional De Saúde). (2011). Museu da Funasa. Acedido a 18 de outubro de 2016. www.funasa.gov.br/site/museu-da-funasa.

IBGE (Instituto Brasileiro de Geografia e Estatística). (2013). Taxa de mortalidade infantil por mil nascidos vivos Brasil - 2000 a 2015. Acedido a 24 de julho de 2017. Retrieved from. http://Brasilemsintese.ibge.gov.br/ populacao/taxas-de-mortalidade-infantil.html

Paim, J. S. (2013). A Constituição Cidadã e os 25 anos do Sistema Único de Saúde (SUS). Cad. Saúde Pública 29(10), 1927-1936. Acedido a 24 de julho de 2017. Retrieved from. http://dx.doi.org/10.1080/15567030701512733.

OMS (Organização mundial da saúde). (2016) Países. Acedido a 18 de outubro de 2016. Retrieved from. http://www.who.int/countries/es/

PNUD. (2015). Relatório de desenvolvimento humano. Etiópia. Communications Development Incorporated. Acedido a 29 de junho de 2016. Retrieved from. http://www.br.undp.org/content/brazil/pt/home/library/relato rios-de-desenvolvimento-humano/relatorio-do-desenvolvimento-humano-200014/ 
RIO DAS OSTRAS. (2017). Projeto de Lei Orçamentaria Anual Exercício 2017. Rio das Ostras.

Rocha, F. L. X. (1998). Direitos fundamentais na constituição de 1988. Themis (2), 109-123. Acedido a 24 de julho de 2017. Retrieved from. https://bdjur.stj.jus.br/jspui/bitstream/2011/25258/direitos_fundamentais_constituicao_ 88.pdf

Secretaria de Estado de Saúde. (2016). Planejamento Regional - Baixada Litorânea Rio de janeiro. Rio de Janeiro. Acedido a 28 de maio de 2016. Retrieved from http://www.saude.rj.gov.br/comum/code/Mostrar Arquivo.php?C=NjMONw\%2C\%2C

SINUS (Simulação das Nações Unidas para secundaristas). (2014). Conferência Internacional de Saúde. Acedido a 28 de maio de 2016. Retrieved from http://sinus.org.br/2014/wp-content/uploads/2013/11/OMS-Guia-Online.pdf

\section{Sobre os Autores}

Yuri Gurgel Borba é bacharel em Engenharia de Produção na Universidade Veiga de Almeida e graduando em Enfermagem na Universidade Federal Fluminense.

Luis Carlos de Barros Loureiro (MsC) é mestre em Economia Empresarial na Universidade Cândido Mendes (2003) e Graduação em Bacharel em Administração na Faculdades Integradas Simonsen (2000), Bacharel em Direito no Centro Universitário Moacyr Sreder Bastos (1989), Licenciatura Plena em Comércio na Faculdade Béthencourt da Silva (1984) e Bacharel em Ciências Contábeis no Centro Universitário Moacyr Sreder Bastos (1982). 